\title{
Intravenous Glucose Suppresses Glucose Production but not Proteolysis in Extremely Premature Newborns
}

\author{
David E. Hertz, Cheryl A. Karn, Ya Mei Liu, Edward A. Liechty, and Scott C. Denne \\ Department of Pediatrics, Section of Neonatal-Perinatal Medicine, Indiana University School of Medicine, \\ Indianapolis, Indiana 46202-5210
}

\begin{abstract}
To ascertain whether the inability to suppress glucose production and increase glucose utilization in response to glucose infusion is an inherent characteristic of immature individuals, we determined glucose rate of appearance $\left(\boldsymbol{R}_{\mathrm{a}}\right)$ in minimally stressed, clinically stable, extremely premature infants $(\sim 26-$ wk gestation) at two glucose infusion rates $(6.2 \pm 0.4$ and $9.5 \pm 0.5 \mathrm{mg} / \mathrm{kg}$ per $\mathrm{min})$. We also assessed whether an increase in glucose delivery suppresses proteolysis by measuring the $\boldsymbol{R}_{\mathrm{a}}$ of phenylalanine and leucine. Glucose $\boldsymbol{R}_{\mathrm{a}}$ (and utilization) increased significantly at the higher glucose infusion rate ( $7.9 \pm 0.5$ vs. $9.8 \pm 0.6 \mathrm{mg} / \mathrm{kg}$ per $\mathrm{min}$ ). Glucose production persisted at the lower glucose infusion rate but was suppressed to nearly zero at the higher rate $(1.7 \pm 0.5 \mathrm{vs} .0 .3 \pm 0.1 \mathrm{mg} / \mathrm{kg}$ per $\mathrm{min}$ ). Proteolysis was unaffected by the higher glucose infusion rate as reflected by no change in the rates of appearance of either phenylalanine ( $96 \pm 5 \mathrm{vs} .95 \pm 3 \mu \mathrm{mol} / \mathrm{kg}$ per h ) or leucine (285 \pm 20 vs. $283 \pm 14 \mu \mathrm{mol} / \mathrm{kg}$ per $\mathrm{h}$ ). Thus, clinically stable, extremely premature infants suppress glucose production and increase glucose utilization in response to increased glucose infusion, demonstrating no inherent immaturity of these processes. In contrast, increasing the rate of glucose delivery results in no change in whole body proteolysis in these infants. The regulation of proteolysis in this population remains to be defined. (J. Clin. Invest. 1993. 92:1752-1758.) Key words: Stable isotope tracers • protein turnover • leucine • phenylalanine $\cdot$ glucose utilization
\end{abstract}

\section{Introduction}

Hyperglycemia ( $>200 \mathrm{mg} / \mathrm{dl}$ ) frequently occurs in premature newborns, especially in those born before 30-wk gestation (1). This propensity toward hyperglycemia is widely regarded as a developmental characteristic (2-5), largely based upon the finding of continued glucose production during intravenous glucose infusion in immature individuals (6-9). However, because other factors (i.e., stress from respiratory distress syndrome, sepsis) often coexist along with immaturity, it has not been clear whether it is immaturity per se that results in aberrant glucose homeostasis. With the advent of surfactant

Address correspondence to Dr. Scott C. Denne, Indiana University School of Medicine, 702 Barnhill Drive (RR 208), Indianapolis, IN 46202-5210.

Received for publication 18 December 1992 and in revised form 12 April 1993.

J. Clin. Invest.

(C) The American Society for Clinical Investigation, Inc.

0021-9738/93/10/1752/07 \$2.00

Volume 92, October 1993, 1752-1758 preparations to ameliorate respiratory distress syndrome, it is now possible to study relatively unstressed, clinically stable, extremely premature ( $<28 \mathrm{wk}$ ) newborns and thereby minimize factors other than immaturity. The present study was performed to ascertain whether the inability to completely suppress glucose production and increase glucose utilization is an inherent characteristic of immature individuals. This is an important issue because glucose is typically the only substrate administered in early neonatal life. To this end, we measured glucose production and utilization in response to an increase in exogenous glucose infusion in clinically stable, extremely premature ( $\sim 26$-wk gestation $)$ newborns during the first days of life.

An issue of equal importance to glucoregulation in extremely premature infants is their capacity to minimize the loss of protein stores while receiving only glucose substrate. In fact, to the extent that amino acids from whole body proteolysis are used for gluconeogenesis to support persistent glucose production, these two issues are related. Intravenous glucose administration in adults results in suppression of glucose production and a corresponding reduction in proteolysis (10). Insulin has been demonstrated to be an important regulator of both processes in mature individuals (11-15). In contrast to the data available in adults, there is currently no information regarding whole body proteolysis or its regulation in extremely premature infants. Therefore, we also determined whether an increase in glucose delivery would suppress proteolysis, thereby sparing endogenous protein stores in these premature newborns.

\section{Methods}

Subjects. Studies were approved by the Institutional Review Board of Indiana University, and written informed consent was obtained from the parents. Study subjects included five clinically stable extremely low birth weight infants ( $<1,100$-g birth wt, $<28$-wk gestation ). The clinical characteristics of the study subjects are summarized in Table I. All infants were appropriate for gestational age, had no congenital anomalies, and were stable on low ventilator settings. The ventilator support required by the infants at the time of the study is also reported in Table I; there were no significant changes in these ventilator settings for the $24 \mathrm{~h}$ before or following the study. None of the infants were receiving or had ever received inotropic support. Three of the five infants had previously received a course of surfactant replacement therapy based on clinical and radiographic evidence of respiratory distress syndrome; the remaining two had no evidence of surfactant deficiency. All five infants were receiving ampicillin and gentamicin, as is standard practice in premature infants, pending the results of their initial blood cultures; however, none of the infants exhibited any clinical signs of sepsis and all cultures were negative. The hematocrit of the infants at the time of study was $39 \pm 1$ (range of 37 to 40 ). As is typical clinical practice in extremely premature infants during the first days of life, intravenous glucose was provided at a rate of $6.4 \pm 0.8 \mathrm{mg} / \mathrm{kg}$ per min for the $24 \mathrm{~h}$ before the study (Table I). Four infants received only intravenous glucose before study; one infant received intravenous amino acids $(2 \mathrm{gm} /$ 


\begin{tabular}{|c|c|c|c|c|c|c|c|c|c|c|c|}
\hline \multirow[b]{2}{*}{ Subject } & \multirow[b]{2}{*}{ Sex } & \multirow[b]{2}{*}{ Gestation age } & \multirow[b]{2}{*}{ Birth weight } & \multirow[b]{2}{*}{ Study weight } & \multirow[b]{2}{*}{ Age at study } & \multirow{2}{*}{$\begin{array}{l}\text { Glucose delivery } \\
\text { before study }\end{array}$} & \multirow{2}{*}{$\begin{array}{l}\text { [Glucose] at } \\
\text { time zero }\end{array}$} & \multicolumn{4}{|c|}{$\begin{array}{l}\text { Ventilator support } \\
\text { during study }\end{array}$} \\
\hline & & & & & & & & PIP & PEEP & Rate & $\mathrm{FiO}_{2}$ \\
\hline & & $w k$ & $g$ & $g$ & $h$ & $m g / k g$ per min & $m g / d l$ & $\mathrm{CmH}_{2} \mathrm{O}$ & $\mathrm{Cm} \mathrm{H}_{2} \mathrm{O}$ & & \\
\hline 1 & $\mathbf{M}$ & 25.5 & 900 & 840 & 62 & 6.9 & 134 & 12 & 4 & 17 & 0.21 \\
\hline 2 & $\mathrm{~F}$ & 27.5 & 1030 & 1049 & 41 & 4.0 & 73 & 18 & 4 & 30 & $0.40-0.60$ \\
\hline 3 & $\mathbf{M}$ & 26.5 & 890 & 760 & 191 & 7.7 & 117 & 18 & 5 & 28 & $0.30-0.40$ \\
\hline 4 & $\mathbf{M}$ & 25 & 840 & 833 & 37 & 4.9 & 175 & 16 & 4 & 20 & 0.30 \\
\hline 5 & $\mathbf{M}$ & 26.5 & 840 & 790 & 17 & 8.3 & 151 & 16 & 4 & 15 & 0.21 \\
\hline Mean & & 26.2 & 900 & 854 & 70 & 6.4 & 130 & & & & \\
\hline SEM & & 0.4 & 35 & 51 & 31 & 0.8 & 17 & & & & \\
\hline
\end{tabular}

PIP, peak inspiratory pressure; PEEP, positive end expiratory pressure; $\mathrm{FiO}_{2}$, fraction of inspired oxygen.

$\mathrm{kg}$ per day $)$ and lipid $(0.5 \mathrm{gm} / \mathrm{kg}$ per $\mathrm{d})$ in addition to glucose. In this one infant, intravenous amino acids and lipid were discontinued $2 \mathrm{~h}$ before the study and glucose alone continued. Caloric intakes were $34 \pm 6 \mathrm{kcal} / \mathrm{kg}$ per $\mathrm{d}$ (range $20-50$ ) in the $24 \mathrm{~h}$ preceding the study. None of the infants had ever received enteral feeding before study. Each infant had an umbilical arterial catheter and venous access present before study.

Protocol. At the beginning of the study, the umbilical artery catheter fluids were changed to normal saline and a baseline blood sample obtained. A priming dose of the tracers (in normal saline) representing $90 \mathrm{~min}$ of infusion, was administered over $5 \mathrm{~min}$. Thereafter, constant infusions of $\left[6,6, \mathrm{~d}_{2}\right]$ glucose $(100 \mu \mathrm{g} / \mathrm{kg}$ per min $),\left[1-{ }^{13} \mathrm{C}\right]$ leucine $(10$ $\mu \mathrm{mol} / \mathrm{kg}$ per $\mathrm{h})$, and $\left[d_{5}\right]$ phenylalanine $(4 \mu \mathrm{mol} / \mathrm{kg}$ per $\mathrm{h})$ were delivered through the venous catheter via an infusion pump (Harvard Apparatus, Inc., South Natick, MA). These tracers were dissolved in unlabeled $D_{10} W$, which was administered at a calculated rate of $6 \mathrm{mg} / \mathrm{kg}$ per min. Tracers were given in $D_{10} W$ so that the total amount of fluids each infant received could be maintained at the prestudy rate. Blood samples were obtained through the arterial catheter at 90,105 , and 120 min, and immediately analyzed for plasma glucose concentration. The remainder of the sample was then frozen at $-70^{\circ} \mathrm{C}$ for later analysis.

After the 120 -min sample, an additional $3 \mathrm{mg} / \mathrm{kg}$ per min of unlabeled glucose was piggybacked into the venous catheter to make the total glucose infusion rate $\sim 9 \mathrm{mg} / \mathrm{kg}$ per min. The tracer isotope infusion was unchanged. Blood samples were again obtained at 210 , 225 , and $240 \mathrm{~min}$, analyzed for plasma glucose, and frozen for later analysis. Syringes containing infusates were weighed before and after infusion to quantitate volume actually delivered. Each infusate was analyzed for glucose concentration and isotopic enrichment to determine the actual unlabeled and tracer glucose infusion rate. The concentrations of leucine and phenylalanine in each infusate were also determined.

All urine output during the study was monitored for the presence of glucose. None of the infants developed glycosuria during the studies.

Analytical methods. Plasma glucose concentrations were determined by the glucose oxidase method (Yellow Springs Instruments, Yellow Springs, $\mathrm{OH}$ ). Plasma insulin concentrations were measured by double-antibody RIA. The plasma enrichments of leucine, phenylalanine, $\alpha$-ketoisocaproic acid (KIC), ${ }^{1}$ and glucose were determined by electron impact ionization and selected ion monitoring on a gas chromatograph mass spectrometer (model 5970; Hewlett-Packard Co., Palo Alto, CA). The enrichment of plasma glucose was measured by monitoring ions 98 and 100 after pentacetate derivatization (16). The enrichments of plasma leucine and phenylalanine were determined by

1. Abbreviations used in this paper: GIR, glucose infusion rate; KIC, $\alpha$-ketoisocaproic acid; NIMGU, noninsulin mediated glucose uptake. monitoring ions 302 and 303 (leucine) and 234 and 239 (phenylalanine) following derivatization to their tertiary butyl dimethyl silyl derivatives (17). The plasma enrichment of KIC was determined following derivatization to the $O$-trimethylsilylquinoxalinol by monitoring ions 232 and 233 (18). The final value for all determinations was corrected using an enrichment calibration curve. The mean enrichment values of three samples taken during enrichment plateau in each subject were used for further analysis. The coefficient of variation was $<5 \%$ at each enrichment plateau.

Calculations. Plasma enrichments of glucose were used in these studies to calculate the total rate of appearance of glucose. Plasma enrichments of leucine, $\mathrm{KIC}$, and phenylalanine were used to calculate the rates of appearance of leucine and phenylalanine. Leucine and phenylalanine were chosen because they are essential amino acids and their rate of appearance in a subject receiving no exogenous protein reflects whole body proteolysis. The enrichment of KIC, the intracellular transamination product of leucine, was also measured as its plasma enrichment has been shown to closely approximate intracellular leucine enrichment (19).

The total rates of appearance of glucose, leucine, and phenylalanine were each calculated by measuring tracer dilution at steady state as modified for stable isotopic tracers $(20,21)$.

$R_{\mathrm{a}}=[100 / E P-1] \times I$

where $R_{\mathrm{a}}$ is the rate of appearance of glucose or amino acid, EP is the steady state enrichment of the specific isotope, and $I$ is the rate of tracer infusion.

Amino acid concentrations were not measured in this study due to the severely limited amount of blood that was obtained at each time point. It is highly likely that amino acid concentrations were at steady state at the end of each of the two periods, as has been demonstrated in studies carried out in adults during infusions of glucose, or glucose and insulin $(10,22,23)$. In any case, it must be noted that at isotopic steady state (Fig. 1), the $R_{\mathrm{a}}$ of leucine and phenylalanine (reflecting proteolysis) is constant (18). If changes in leucine and phenylalanine concentrations do occur during isotopic steady state, this must be a consequence of altered rate of disappearance $\left(R_{\mathrm{d}}\right)$ with regard to leucine/ phenylalanine used for protein synthesis or oxidative metabolism (18), but not measured in this study.

Glucose production was calculated as the difference between the total rate of appearance of glucose and the rate of intravenous glucose delivery. Using such a calculation, underestimation of glucose production has been well described in studies employing the glucose clamp technique, resulting in negative glucose production values (24-27). Impurities in the radioactive glucose tracer may explain some of these findings (27). In addition, rapid alterations in exogenous glucose infusion during insulin administration are also likely to contribute to the 


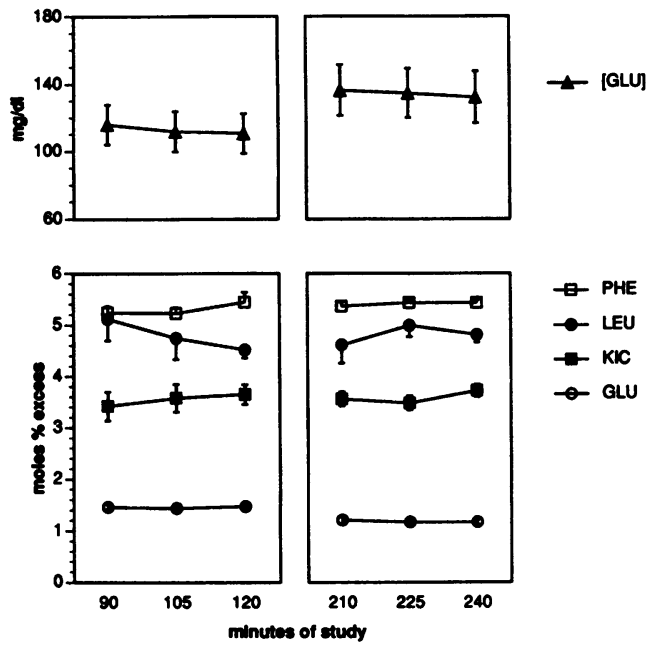

Figure 1. Glucose concentration and tracer enrichments measured during the studies. The conditions on the left correspond to $\mathrm{GIR}_{1}$, the conditions on the right correspond to $\mathrm{GIR}_{2}$.

problem (26). Although a relative underestimation of glucose production in the present study cannot be completely excluded, the magnitude of such an underestimation is likely to be small because: $(a)$ the exogenous glucose infusion rate was not altered within each study period, $(b)$ isotopic steady state was readily apparent during each period (coefficient of variation was $2.6 \pm 0.3 \%$ ), and (c) total glucose $R_{\mathrm{a}}$ measured by isotope dilution closely approximated exogenous glucose delivery during the higher glucose infusion rate, and no negative glucose production rates were measured.

Statistics. All results are reported as the mean \pm SEM. Comparisons were made using the paired $t$ test.

\section{Results}

Actual glucose infusion rates (GIR) were $6.24 \pm 0.38 \mathrm{mg} / \mathrm{kg}$ per $\min \left(G_{1 R}\right)$ and $9.46 \pm 0.54 \mathrm{mg} / \mathrm{kg}$ per $\min \left(\mathrm{GIR}_{2}\right)$. Steady state concentrations of glucose were achieved at both rates (Fig. 1). There was a modest $(\sim 20 \%)$ increase in glucose concentration $(P=0.07)$ in response to the higher glucose infusion rate (Fig. 1, Table II). In contrast, there was a substantial ( $>300 \%$ ) increase in insulin concentration at the higher glucose infusion rate ( Table II). These insulin concentrations and the magnitude of change in response to glucose infusion are similar to previous studies in premature newborns $(28,29)$.

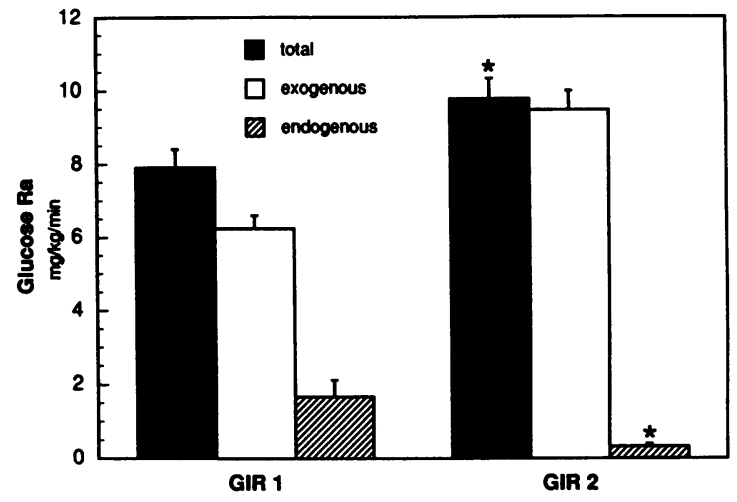

Figure 2. Glucose kinetics during the two different glucose infusion rates $\left({ }^{*} P<0.05\right)$.

Isotopic steady state was achieved for the glucose and amino acid tracers as demonstrated in Fig. 1. Glucose kinetics for each subject are shown in Table II; these results are graphically displayed in Fig. 2. Total glucose $R_{\mathrm{a}}$ significantly increased at the higher glucose infusion rate; because steady state was achieved for both tracer enrichment and glucose concentration, and no glucose was present in the urine of these newborns, these total glucose $R_{\mathrm{a}}$ values also represent glucose utilization rates $\left(R_{\mathrm{d}}\right)$. Glucose production made an important contribution (20\%) to total glucose $R_{\mathrm{a}}$ at the lower rate of glucose infusion, but was suppressed to nearly zero ( $3 \%$ of total $R_{\mathrm{a}}$ ) at the higher rate (Fig. 2).

The significant relationship between glucose utilization rate and insulin concentration is shown in Fig. 3 ( $y=0.24 x$ $\left.+6.87, r^{2}=0.843, P<0.001\right)$. As expected, this relationship is linear at the relatively low insulin concentrations measured in this study. A similar but considerably weaker relationship between glucose utilization and glucose concentration is shown in Fig. $4\left(y=0.03 x+4.76, r^{2}=0.475, P=0.03\right)$. As the figure demonstrates, three high glucose values are responsible for this correlation; if one of these values is eliminated, the correlation is no longer significant.

The rates of appearance of leucine and phenylalanine (reflecting proteolysis) at both glucose infusion rates are reported in Table III. Leucine $R_{\mathrm{a}}$ is calculated, based on both the plasma enrichment of KIC (reciprocal pool model) and plasma leucine (primary pool model). The ratio of KIC to leucine enrichment in these premature newborns was $0.73 \pm 0.03$ at the lower

Table II. Glucose Kinetics, and Insulin and Glucose Concentrations Measured at Two Different Glucose Infusion Rates

\begin{tabular}{|c|c|c|c|c|c|c|c|c|}
\hline \multirow[b]{3}{*}{ Subject } & \multicolumn{2}{|c|}{ Total $R_{a}$} & \multicolumn{2}{|c|}{ Endogenous $R_{\mathbf{a}}$} & \multicolumn{2}{|c|}{ Glucose concentration } & \multicolumn{2}{|c|}{ Insulin concentration } \\
\hline & \multicolumn{2}{|c|}{$m g / k g$ per min } & \multicolumn{2}{|c|}{$m g / k g$ per min } & \multicolumn{2}{|c|}{$m g / d l$} & \multicolumn{2}{|c|}{$\mu U / m l$} \\
\hline & $\mathrm{GIR}_{1}$ & $\mathbf{G I R}_{2}$ & $\mathrm{GIR}_{1}$ & $\mathrm{GIR}_{2}$ & $\mathrm{GIR}_{1}$ & $\mathrm{GIR}_{2}$ & GIR $_{1}$ & $\mathrm{GIR}_{2}$ \\
\hline 1 & 8.16 & 11.36 & 0.77 & 0.18 & 110 & 167 & 2 & 17 \\
\hline 2 & 7.98 & 10.37 & 1.37 & 0.46 & 96 & 106 & 5 & 17 \\
\hline 3 & 6.53 & 8.84 & 0.88 & 0.26 & 97 & 112 & 2 & 10 \\
\hline 4 & 9.49 & 9.98 & 3.17 & 0.49 & 159 & 178 & 7 & 13 \\
\hline 5 & 7.40 & 8.30 & 2.17 & 0.19 & 102 & 118 & 5 & 7 \\
\hline Mean & 7.91 & $9.77^{*}$ & 1.67 & $0.32^{*}$ & 113 & $136^{\ddagger}$ & 4 & $13^{*}$ \\
\hline SEM & 0.49 & 0.55 & 0.45 & 0.07 & 12 & 15 & 1 & 2 . \\
\hline
\end{tabular}

$(\mathrm{GIR}) * P<0.05,{ }^{\ddagger} P=0.07$ 


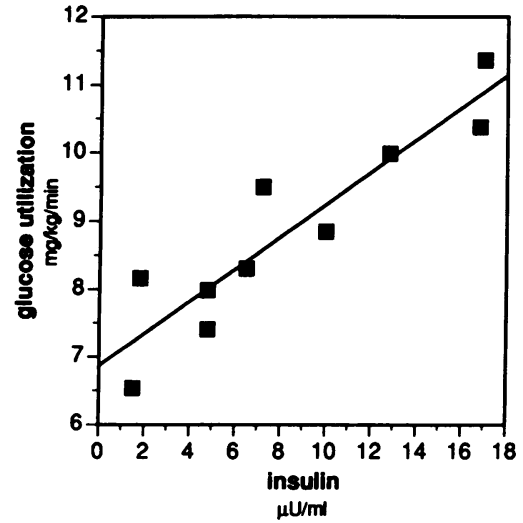

Figure 3. Relationship between insulin concentration and glucose utilization $(y=0.24 x$ $+6.87, r^{2}=0.843, P$
$<0.001)$

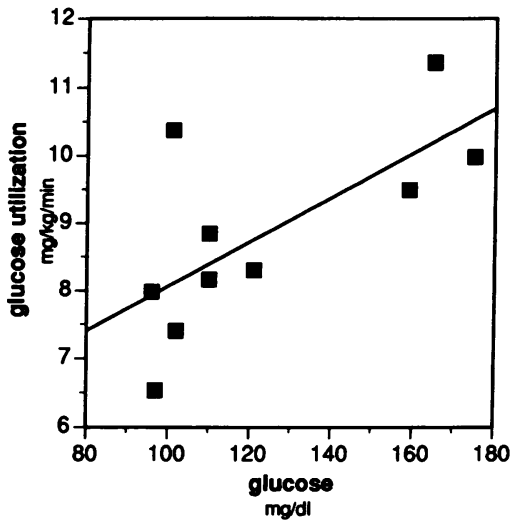

Figure 4. Relationship between glucose concentration and glucose utilization $(y=0.03 x$ $+4.76, r^{2}=0.475, P$ $=0.03$ ). glucose infusion rate, and was unchanged $(0.75 \pm 0.04)$ at the higher glucose infusion rate. These ratios are similar to those previously reported in studies in human adults (19). As shown in Table III, rates of appearance of leucine (using both KIC and leucine enrichments) and phenylalanine were virtually identical at the two glucose infusion rates. Thus, no reduction in proteolysis in response to an increase in glucose delivery was measured.

\section{Discussion}

In the present study we examined the effect of two rates of intravenous glucose delivery on glucose production and proteolysis in the extremely low birth weight infant during the first days of life. The data demonstrate that although glucose production continues at a significant rate when $6 \mathrm{mg} / \mathrm{kg}$ per min of glucose is provided, at $9 \mathrm{mg} / \mathrm{kg}$ per min glucose production is suppressed to nearly zero. In contrast, rates of proteolysis are not reduced by the higher glucose delivery rate.

Glucose production and its regulation have been extensively studied in human adults. Basal rates of glucose release determined after an overnight fast have been measured at $2-2.5 \mathrm{mg} / \mathrm{kg}$ per $\min (10-14)$. When intravenous glucose is infused at a rate slightly exceeding basal glucose $R_{\mathrm{a}}(3-4 \mathrm{mg} / \mathrm{kg}$ per min), glucose production effectively ceases $(6,11)$. This suppression of glucose production is accompanied by increases in the plasma concentration of glucose $(\sim 135 \mathrm{mg} / \mathrm{dl})$ and insulin $(\sim 20-25 \mu \mathrm{U} / \mathrm{ml})(11)$. Glucose and insulin clamp studies have demonstrated that these increases in glucose and insulin concentrations both contribute to the suppression of glucose production (11-13). Insulin alone can suppress glucose production without increases in glucose concentration, but higher concentrations of insulin $(\sim 60 \mu \mathrm{U} / \mathrm{ml})$ are required for complete suppression (13). Similarly, elevations in glucose concentration alone can also suppress glucose production; near complete suppression of glucose production has been achieved by hyperglycemia at basal insulin concentrations in some studies (11) but not others (12). Although the exact contributions of insulin and glucose to the complete suppression of glucose production during intravenous glucose infusion may not be completely defined, it is likely that both play a significant role in adult glucose homeostasis.

In contrast to the adult, neonatal glucose production and regulation is less completely studied; this is particularly true in the extremely low birth weight newborn. Because of the fragile nature of this population, a true basal (fasting) glucose production rate cannot be obtained. However, we suggest that the total glucose $R_{\mathrm{a}}$ of $7.9 \mathrm{mg} / \mathrm{kg}$ per min, measured in the present study during the infusion of $6 \mathrm{mg} / \mathrm{kg}$ per min of glucose, represents a reasonable approximation of basal glucose production (and utilization ) in these infants. A nearly identical total glucose $R_{\mathrm{a}}$ $(7.7 \mathrm{mg} / \mathrm{kg}$ per $\mathrm{min}$ ) was determined in extremely low birth weight infants during a substantially lower $(4.2 \mathrm{mg} / \mathrm{kg}$ per $\mathrm{min}$ ) intravenous glucose infusion, providing additional support for this approximate basal rate (30). This estimated glucose production rate is significantly higher than that measured in adults, and is also higher than the $3-5 \mathrm{mg} / \mathrm{kg}$ per min we and

Table III. Leucine and Phenylalanine $R_{a}$ Measured at Two Different Glucose Infusion Rates

\begin{tabular}{|c|c|c|c|c|c|c|}
\hline \multirow[b]{3}{*}{ Subject } & \multicolumn{2}{|c|}{ Leucine $R_{a}($ Leu $)$} & \multicolumn{2}{|c|}{ Leucine $R_{a}(\mathrm{KIC})$} & \multicolumn{2}{|c|}{ Phenylalanine $R_{a}$} \\
\hline & \multicolumn{2}{|c|}{$\mu \mathrm{mol} / \mathrm{kg}$ per $\mathrm{h}$} & \multicolumn{2}{|c|}{$\mu \mathrm{mol} / \mathrm{kg}$ per $h$} & \multicolumn{2}{|c|}{ umol/kg per $h$} \\
\hline & $\mathrm{GIR}_{1}$ & $\mathrm{GIR}_{2}$ & $\mathrm{GIR}_{1}$ & $\mathrm{GIR}_{2}$ & $\mathrm{GIR}_{1}$ & $\mathrm{GIR}_{2}$ \\
\hline 1 & 281 & 277 & 365 & 331 & 98 & 97 \\
\hline 2 & 179 & 211 & 263 & 276 & 78 & 83 \\
\hline 3 & 225 & 211 & 275 & 270 & 98 & 93 \\
\hline 4 & 188 & 212 & 258 & 288 & 102 & 102 \\
\hline 5 & 171 & 154 & 264 & 249 & 106 & 99 \\
\hline Mean & 209 & 213 & 285 & 283 & 96 & 95 \\
\hline SEM & 20 & 20 & 20 & 14 & 5 & 3 \\
\hline
\end{tabular}

Leucine $R_{\mathrm{a}}$ is reported, based upon both the enrichment of plasma leucine (primary pool model) and plasma KIC (reciprocal pool model). 
others have determined in full-term newborns $(31,32)$. This is not surprising in view of the high brain/body weight ratio of these extremely low birth weight infants (33), and the virtual absence of fat stores.

Previous studies have measured persistent glucose production during glucose infusion in both immature animals and humans $(6-9,34)$. This has resulted in the widespread acceptance of the concept that there is a developmental immaturity in glucose homeostasis (2-5). Hepatic and/or peripheral insulin insensitivity in immature individuals has been suggested as the likely mechanism $(1,6,35)$. However, it has been questioned whether stress (from anesthesia or blood drawing) or previous feedings (and not achieving a true postabsorptive state) may have played a role in the finding of persistent glucose production (36). Currently, the existence of a specific developmental immaturity in glucose homeostasis independent of these other factors is uncertain. In the present study, we minimized the effect of stress (the neonates were stable, and ventilated, and blood was drawn through indwelling catheters), eliminated the effect of previous feedings (none of the infants had ever been fed), and maximized the possible effect of immaturity by studying the most premature infants in early neonatal life. We were therefore able to evaluate the effect of immaturity per se on glucose homeostasis. The results clearly indicate that when glucose is delivered at a rate that slightly exceeds the estimated basal rate of glucose production, glucose release is suppressed to nearly zero in these extremely immature individuals. This response is the same as that observed in the human adult; we must also point out that this suppression in these extremely immature individuals occurs at glucose concentrations similar to that of the adult $(136 \mathrm{mg} / \mathrm{dl})$ and at lower insulin concentrations $(13 \mu \mathrm{U} / \mathrm{ml})$. These findings definitely do not support a specific developmental immaturity in glucose homeostasis.

Since we did not clamp insulin or glucose in this study, it is not possible to clearly separate the effect of glucose and insulin on the suppression of glucose production. As in adults, it is likely that both play a role. However, the data suggest that changes in plasma insulin concentration may be the more predominant regulator in this population. The mean change in the plasma glucose concentration at the higher glucose infusion rate was only $20 \mathrm{mg} / \mathrm{dl}$ (and of marginal statistical significance). In fact, the glucose concentration increased by $<15 \%$ in three of the five newborns (Table II). In contrast, the mean plasma insulin concentration increased more than threefold at the higher glucose infusion rate, and the minimum individual increase was $\sim 40 \%$. Although not definitive, these data support the fundamental role of insulin in the control of hepatic glucose release in immature individuals. Further, because near complete suppression of glucose release is achieved at low insulin concentrations, the data are inconsistent with the notion of hepatic insulin resistance in this population.

As in the human adult, insulin appears to be an important regulator of total glucose utilization in the extremely premature neonate; Fig. 4 shows the strong relationship between insulin concentration and glucose utilization rate. On a $\mathrm{mg} / \mathrm{kg}$ basis, higher glucose utilization rates are achieved at substantially lower insulin concentrations in extremely premature infants, compared with adults. This is likely due to the fact that the brain makes a much larger contribution to total body weight in the extremely premature infant compared to the adult, and thus the rate $(\mathrm{mg} / \mathrm{kg})$ of noninsulin mediated glu- cose uptake (NIMGU) will be substantially higher $(33,37)$. In this regard, an estimate of NIMGU in extremely low birth weight infants can be obtained from Fig. 4 by extrapolating glucose utilization at zero insulin $(6.9 \mathrm{mg} / \mathrm{kg}$ per min $)$. Thus, NIMGU accounts for approximately $85 \%$ of estimated basal glucose disposal in extremely low birth weight infants, similar to the $75-85 \%$ obtained in normal adults $(37,38)$.

We again acknowledge that because glucose concentration was not actively clamped during these studies, glucose utilization rates were likely affected by the plasma level of glucose as well as insulin. Indeed, we have shown a relationship (albeit a weak one) between glucose concentration and glucose utilization (Fig. 4). Note, however, that this relationship is driven by a few high glucose values; if even one of these values is eliminated the correlation is no longer significant. In contrast, the correlation between insulin and glucose utilization is robust. In fact, if this relationship is examined at "euglycemia" (using insulin concentrations corresponding to glucose levels of 96110 , and excluding the high glucose determinations), there is still a highly significant correlation between insulin and glucose utilization ( $r=0.91, P=0.01)$. This suggests that insulin exerts an independent effect on peripheral glucose uptake in extremely immature individuals, even at low concentrations and with relatively small changes. In any case, the data are not consistent with significant peripheral insulin resistance as a result of immaturity alone.

We must note that in clinical settings hyperglycemia occurs with some frequency in premature newborns (1). Certainly, persistence of glucose production and/or peripheral insulin resistance may play a role in elevations in glucose concentrations. However, our data suggest that it is not immaturity per se but other factors such as stress and sepsis that produce the changes resulting in hyperglycemia (39). In this regard, glucose infusion rates of $<8 \mathrm{mg} / \mathrm{kg}$ per min have been recommended in an effort to avoid hyperglycemia in extremely premature infants $(3,4)$. However, it appears evident from the present study that $8 \mathrm{mg} / \mathrm{kg}$ per min is likely to be the minimal rate of glucose utilization required to fulfill the needs of these infants; glucose infusion rates of $<8 \mathrm{mg} / \mathrm{kg}$ per min are accompanied by supplemental glucose production. Therefore, in clinically stable extremely premature infants without sepsis or significant stress, a glucose infusion rate of $8 \mathrm{mg} / \mathrm{kg}$ per min may be an appropriate target in helping maintain endogenous substrate reserves.

We have also evaluated the effect of an increased glucose delivery rate on proteolysis in extremely premature infants to ascertain whether suppression of glucose production would spare protein stores through the mechanism of reduced whole body proteolysis. Modeling proteolysis is clearly more complex than assessing glucose kinetics, and the assumptions and limitations in accurately assessing proteolysis have been extensively discussed (40). Therefore, to provide a more confident estimate of proteolysis, we traced the rates of appearance into plasma of two essential amino acids, leucine and phenylalanine. In addition, we also measured the enrichment of KIC, which is likely to reflect the intracellular enrichment of leucine, thereby providing a more accurate assessment of whole body proteolysis. Because there was no source of exogenous amino acids during the studies, each of these three determinations should reflect proteolysis. The combination of all these independent measurements adds credibility to the assessment of overall proteolysis. 
In these extremely premature infants, proteolysis by any of the three estimates was unchanged at the higher glucose infusion rate, despite clear increases in insulin concentration and near complete suppression of glucose production. This is in contrast to adult studies, where suppression of glucose production is accompanied by suppression of whole body proteolysis $(10,14,41)$. Robert et al. infused glucose at a rate slightly higher than basal production ( $4 \mathrm{mg} / \mathrm{kg}$ per $\mathrm{min}$ ) in normal adults and demonstrated a $28 \%$ reduction in leucine rate of appearance along with suppression of glucose production (10). This suppression of proteolysis is mediated by insulin, with $30-40 \mu \mathrm{U} / \mathrm{ml}$ necessary for half-maximal suppression $(15,22$, 42 ). Even when insulin concentrations are raised to only 9-16 $\mu \mathrm{U} / \mathrm{ml}$ ( similar to the present study) with the glucose clamp technique in adults, there is a consistent, albeit modest, 10$15 \%$ reduction in proteolysis $(14,15,41)$. It must be pointed out that these studies in adults were carried out at euglycemia, whereas somewhat higher glucose concentrations were obtained during both glucose infusion rates employed in the present study. If hyperglycemia itself suppresses proteolysis, it is conceivable that these higher glucose concentrations may have affected our ability to detect reductions in proteolysis. However, this seems unlikely, in view of recent work by Heiling et al., demonstrating no independent effect of plasma glucose concentration on endogenous whole body proteolysis (43). Thus, the data obtained in the present study suggest that glucose and amino acid metabolism are differently sensitive to the action of insulin in extremely premature infants.

Differential sensitivity of glucose and amino acid metabolism to insulin has also been described in adults under certain circumstances, e.g., Type II diabetes, obesity, bedrest, and 4-d fasting $(14,42,44-46)$. However, the differential insulin sensitivity was precisely opposite to that observed in extremely premature infants. In the adult studies, the ability of insulin to stimulate glucose utilization and/or suppress glucose production was shown to be resistant, whereas the ability of insulin to suppress proteolysis remained normally sensitive.

The exact reasons for these differences between extremely premature infants and adults in the ability to suppress proteolysis are not clear. However, there are a number of possible explanations. Although glucose homeostasis may be established at relatively low concentrations of insulin in extremely immature neonates, there may be less tissue sensitivity to insulin's antiproteolytic effect. Alternatively, the differences in body composition between the extremely low birthweight infant and adults may be important. Relative to adults, skeletal muscle represents a much smaller proportion of body mass in premature infants; it has been demonstrated that the antiproteolytic effect of insulin is more pronounced in skeletal muscle than in nonmuscle tissues (47). It may therefore be more difficult to achieve reductions in proteolysis at the whole body level, with small changes in insulin concentration, in extremely low birthweight infants. It is also possible that regulators other than insulin may play a more significant role in suppression of proteolysis in immature individuals. For example, the effect of plasma amino acid concentrations may be a prominent factor (23). Finally, it is conceivable that high rates of proteolysis in immature individuals are fundamental to the growth process in providing a continuing amino acid source for tissue remodeling and protein accretion $(48,49)$. The highest rates of protein turnover have been repeatedly demonstrated in the most immature individuals with the highest growth potential $(50,51)$.
The present data are consistent with these findings, as leucine flux measurements in these extremely premature infants are $30 \%$ higher than we have determined in full-term newborns (52), and three times higher than in adults $(15,52)$. If high rates of protein turnover are necessary for achieving normal growth, then suppression of proteolysis may be counterproductive; immature tissues may be relatively unresponsive to all antiproteolytic mediators. It is possible that growth hormone plays a role in this process, as recent evidence has indicated that growth hormone antagonizes insulin's antiproteolytic action (49). Clearly, at this point, these issues remain to be resolved.

Although the higher glucose infusion rate did not produce protein sparing by the mechanism of reduced proteolysis, it does not necessarily follow that no protein sparing occurred. Amino acids released from proteolysis can be reutilized for protein synthesis, or be oxidized. We did not measure amino acid oxidation in this study, but it is certainly possible that a higher glucose infusion rate reduced amino acid oxidation and increased reutilization for protein synthesis. There is, in fact, evidence that glucose infusion can result in protein sparing by such a mechanism in studies carried out in the sheep fetus (53).

In summary, clinically stable, extremely premature infants demonstrate a normal glucoregulatory response to increased glucose infusion by both suppressing glucose production and increasing glucose utilization. These results suggest that there is no inherent immaturity in this physiologic response, and that aberrations in glucose homeostasis in this population may be largely due to other coexisting factors. Conversely, although extremely premature infants exhibit an adult-like glucoregulatory response to increases in glucose infusion, the effect upon whole body proteolysis is different. Despite a clear suppression of glucose production, proteolysis is not reduced by a higher glucose delivery rate. The regulators of proteolysis in this population remain to be defined.

\section{Acknowledgments}

This work is supported in part by the National Institutes of Health (grants M-01 RR750, P-60DK20542, K-08-HD-00840, and R-01-HD29153), the James Whitcomb Riley Memorial Association, and by Bristol-Meyers Squibb Inc.

\section{References}

1. Pildes, R. S. 1986. Neonatal hyperglycemia. J. Pediatr. 109:905-7.

2. DiGiacomo, J. E. 1991. Carbohydrates: Metabolism and disorders. In Neonatal nutrition and metabolism. W. W. Hay, editor. Mosby-Year Book Inc., St. Louis. 93-109.

3. Pildes, R. S., and L. D. Lilien. 1992. Carbohydrate disorders. In NeonatalPerinatal Medicine-Diseases of the Fetus and Infant. A. A. Fanaroff and R. J. Martin, editors. Mosby-Year Book Inc., St. Louis. 1152-1180.

4. Kliegman, R. M., and M. K. Wald. 1986. Problems in metabolic adaptation: glucose, calcium, and magnesium. In Care of the High Risk Neonate. M. H. Klaus, and A. A. Fanaroff, editors. W. B. Saunders Co., Philadelphia. 220-238.

5. Cowett, R. M. 1992. Hypoglycemia and hyperglycemia in the newborn. In Fetal and Neonatal Physiology. R. A. Polin and W. W. Fox, editors. W. B. Saunders Co., Philadelphia. 406-418.

6. Cowett, R. M., W. Oh, and R. Schwartz. 1983. Persistent glucose production during glucose infusion in the neonate. J. Clin. Invest. 71:467-475.

7. Cowett, R. M., J. B. Susa, W. Oh, and R. Schwartz. 1978. Endogenous glucose production during constant glucose infusion in the newborn lamb. $P e$ diatr. Res. 12:853-857.

8. Varma, S., H. Nickerson, J. S. Cowan, and J. Hetenyi, Jr. 1973. Homeostatic responses to glucose loading in newborn and young dogs. Metab. Clin. Exp. 22:1367-1375.

9. Sherwood, W. G., D. E. Hill, and G. W. Chance. 1977. Glucose homeostasis in preterm rhesus monkey neonates. Pediatr. Res. 11:874-877.

10. Robert, J., D. M. Bier, X. H. Zhao, D. E. Matthews, and V. R. Young. 1987. Glucose and insulin effects on de novo amino acid synthesis in young men: 
studies with stable isotope labeled alanine, glycine, leucine and lysine. Metab. Clin. Exp. 31:1210-1218.

11. Wolfe, R. R., J. H. F. Shaw, F. Jahoor, D. N. Herndon, and M. H. Wolfe. 1986. Response to glucose infusion in humans: role of changes in insulin concentration. Am. J. Physiol. 250:E306-E311.

12. Sacca, L., D. Vitale, M. Cicala, B. Timarco, and B. Ungaro. 1981. The glucoregulatory response to intravenous glucose infusion in normal man: roles of insulin and glucagon. Metab. Clin. Exp. 30:357-461.

13. Rizza, R. A., L. J. Mandarino, and J. E. Gerich. 1981. Dose-response characteristics for effects of insulin on production and utilization of glucose in man. Am. J. Physiol. 240:E630-E639.

14. Jensen, M. D., J. M. Miles, J. E. Gerich, P. E. Cryer, and M. W. Haymond. 1988. Preservation of insulin effects on glucose production and proteolysis during fasting. Am. J. Physiol. 254:E700-E707.

15. Fukagawa, N. K., K. L. Minaker, J. W. Rowe, M. N. Goodman, D. E. Matthews, D. M. Bier, and V. R. Young. 1985. Insulin-mediated reduction of whole body protein breakdown. J. Clin. Invest. 76:2306-2311.

16. Kalhan, S. C., K. T. Tserng, C. Gilgillan, and L. J. Dierker. 1982. Metabolism of urea and glucose in normal and diabetic pregnancy. Metab. Clin. Exp. 31:834-833.

17. Schwenk, W. F., P. J. Berg, B. Beaufrere, J. M. Miles, and M. W. Haymond. 1984. Use of $t$-butyldimethylsilylation in the gas chromatographic/mass spectrometric analysis of physiologic compounds found in plasma using electronimpact ionization. Anal. Biochem. 141:101-109.

18. Wolfe, R. R. 1992. Radioactive and Stable Isotope Tracers in Biomedicine-Principles and Practice of Kinetic Analysis. Wiley-Liss, Inc., New York. $471 \mathrm{pp}$.

19. Matthews, D. E., H. P. Schwartz, R. D. Yang, K. J. Motil, V. R. Young, and D. M. Bier. 1982. Relationship of plasma leucine and alpha-ketoisocaproate during a $\mathrm{L}-\left[1-{ }^{13} \mathrm{C}\right]$ leucine infusion in man: a method for measuring human intracellular leucine tracer enrichment. Metab. Clin. Exp. 31:1105-1112.

20. Steele, R. 1959. Influence of glucose loading and of injected insulin on hepatic glucose output. Proc. NY Acad. Sci. 82:420-430.

21. Tserng, K. Y., and S. C. Kalhan. 1983. Calculation of substrate turnover rate in stable isotope tracer studies. Am. J. Physiol. 245:E308-E311.

22. Tessari, P., R. Trevisan, S. Inchiostro, G. Biolo, R. Nosadini, S. Vigili De Kreutzenberg, E. Duner, A. Tiengo, and G. Crepaldi. 1986. Dose-response curves of effects of insulin on leucine kinetics in humans. Am. J. Physiol. 251:E334-E342.

23. Flakoll, P. J., M. Kulaylat, M. Frexes-Steed, H. Hourani, L. L. Brown, J. O. Hill, and N. N. Abumrad. 1989. Amino acids augment insulin's suppression of whole body proteolysis. Am. J. Physiol. 257:E839-E847.

24. Argoud, G. M., D. S. Schade, and R. P. Eaton. 1987. Underestimation of hepatic glucose production by radioactive and stable tracers. Am. J. Physiol. 252:E606-E615.

25. Finegood, D. T., R. N. Bergman, and M. Vranic. 1987. Estimation of endogenous glucose production during hyperinsulinemic-euglycemic glucose clamps. Comparison of unlabeled and labeled exogenous glucose infusates. Diabetes. 36:914-24.

26. Elahi, D., G. S. Meneilly, K. L. Minaker, D. K. Andersen, and J. W. Rowe. 1989. Escape of hepatic glucose production during hyperglycemic clamp. Am. J. Physiol. 257:E704-E711.

27. Schwenk, W. F., P. C. Butler, M. W. Haymond, and R. A. Rizza. 1990. Underestimation of glucose turnover corrected with high-performance liquid chromatography purification of $\left[6-{ }^{3} \mathrm{H}\right]$ glucose. Am. J. Physiol. 258:E228-E233.

28. Grasso, S., A. Messina, G. Distefano, R. Vigo, and G. Reitano. 1973. Insulin secretion in the premature infant. Response to glucose and amino acids. Diabetes. 22:349-353.

29. Grasso, S., F. Fallucca, M. G. Romeo, G. Distefano, E. Sciullo, and G. Reitano. 1990. Glucagon and insulin secretion in low birthweight preterm infants. The effect of glucose infusion. Acta Paediatr. Scand. 79:280-285.

30. Tyrda, E. E., X. Chen, and G. Boden. 1992. Glucose production and utilization in the $<1000$ gram infant. Pediatr. Res. 31:296 A. (Abstr.)
31. Kalhan, S. C., S. M. Savin, and P. A. J. Adam. 1976. Measurement of glucose turnover in the human newborn with glucose $1-{ }^{13} \mathrm{C}$. J. Clin. Endocrinol. \& Metab. 43:704-707.

32. Denne, S. C., and S. C. Kalhan. 1986. Glucose carbon recycling and oxidation in human newborns. Am. J. Physiol. 251:E71-E77.

33. Dobbing, J., and J. Sands. 1973. Quantitative growth and development of the human brain. Arch. Dis. Child. 48:757-767.

34. Cowett, R. M., G. E. Anderson, C. A. Maguire, and W. Oh. 1988. Ontogeny of glucose homeostasis in low birth weight infants. J. Pediatr. 112:462-465.

35. Goldman, S. L., and T. Hirata. 1980. Attenuated response to insulin in very low birthweight infants. Pediatr. Res. 14:50-53.

36. Kalhan, S. C., A. Oliven, K. C. King, and C. Lucero. 1986. Role of glucose in the regulation of endogenous glucose production in the human newborn. $P e-$ diatr. Res. 20:49-52.

37. Baron, A. D., O. G. Kolterman, J. Bell, L. J. Mandarino, and J. M. Olefsky. 1985. Rates of noninsulin-mediated glucose uptake are elevated in type II diabetic subjects. J. Clin. Invest. 76:1782-1788.

38. Gottesman, I., L. J. Mandarino, and J. Gerich. 1983. Estimation and kinetic analysis of insulin dependent glucose uptake in human subjects. Am. J. Physiol. 2244:E6322-E6325.

39. Virkamäki, A., I. Puhakainen, V. A. Koivisto, H. Vuorinen-Markkola, and H. Yki-Järvinen. 1992. Mechanisms of hepatic and peripheral insulin resistance during acute infections in humans. J. Clin. Endocrinol. \& Metab. 74:673679.

40. Bier, D. 1989. Intrinsically difficult problems: the kinetics of body proteins and amino acids in man. Diabetes Metab. Rev. 5:111-132.

41. Jensen, M. D., and M. W. Haymond. 1991. Protein metabolism in obesity: effects of body fat distribution and hyperinsulinemia on leucine turnover Am. J. Clin. Nutr. 53:172-176.

42. Shangraw, R. E., C. A. Stuart, M. J. Prince, E. J. Peters, and R. R. Wolfe. 1988. Insulin responsiveness of protein metabolism in vivo following bedrest in humans. Am. J. Physiol. 255:E548-E558.

43. Heiling, V. J., P. J. Campbell, I. S. Gottesman, E. Tsalikian, B. Beaufrere, J. E. Gerich, and M. W. Haymond. 1993. Differential effects of hyperglycemia and hyperinsulinemia on leucine rates of appearance in normal humans. J. Clin. Endocrinol. \& Metab. 76:203-206.

44. Staten, M. A., D. E. Matthews, and D. M. Bier. 1987. Leucine metabolism in type II diabetes mellitus. Diabetes. 35:1249-53.

45. Well, S., and K. S. Nair. 1990. Failure of glyburide and insulin treatment to decrease leucine flux in obese type II diabetic patients. Int. J. Obes. 14:701710 .

46. Caballero, B., and R. J. Wurtman. 1991. Differential effects of insulin resistance on leucine and glucose kinetics in obesity. Metab. Clin. Exp. 40:51-58.

47. Denne, S. C., E. A. Liechty, Y. M. Liu, G. Brechtel, and A. Baron. 1991. Proteolysis in skeletal muscle and whole body in response to euglycemic hyperinsulinemia in normal adults. Am. J. Physiol. 261:E809-E814.

48. Scornik, O. A. 1982. Protein synthesis and degradation during growth. In Biochemical Development of the Fetus and Neonate. L. T. Jones, editor. Elsevier Biomedical Press, New York. 866-94.

49. Fryburg, D. A., R. J. Louard, K. E. Gerow, R. A. Gelfand, and E. J. Barrett. 1992. Growth hormone stimulates skeletal muscle protein synthesis and antagonizes insulin's antiproteolytic action in humans. Diabetes. 41:424-429.

50. Goldspink, D. K., and F. J. Kelly. 1984. Protein turnover and growth in the whole body liver, and kidney of the rat from the foetus to senility. Biochem. $J$. 217:507-516

51. Catzeflis, C., Y. Schultz, J. L. Micheli, C. Welsh, M. J. Arnaud, and E. Jequier. 1985 . Whole body protein synthesis and energy expenditure in very low birth weight infants. Pediatr. Res. 19:679-87.

52. Denne, S. C., and S. C. Kalhan. 1987. Leucine metabolism in human newborns. Am. J. Physiol. 253:E608-E615.

53. Liechty, E. A., S. C. Denne, J. A. Lemons, and C. L. Kein. 1991. Effects of glucose infusion on leucine transamination and oxidation in the ovine fetus. Pediatr. Res. 30:423-429. 